\title{
Research on the Ecological Dilemma Analysis and Countermeasures of Chinese College English Education
}

\author{
Qing Song \\ School of Foreign Languages, Kunming University, Kunming, China \\ 932821517@qq.com
}

\begin{abstract}
Keywords: college English education; ecological dilemma analysis; English education reform
\end{abstract}
\begin{abstract}
The college English education is a unique ecological system that is composed of unique ecological subject and ecological environment, which is influenced by a variety of factors within and outside the system, and has special properties such as interactivity, professionalism and culture. The plight of the college English education in our country includes the imbalance of ecological principal position, disjointed ecological chain, and incongruous ecological environment. The effective way out of this dilemma is to build an interactive, open, autonomous and harmonious ecosystem of education. In practice, we need to establish the education, the integrated education chain, the interactive education method and the open and harmonious education environment.
\end{abstract}

\section{Introduction}

The college English education refers to the public English language education, which is not an English major [1]. Since the 1980s, education has undergone several reforms, but overall, the "time-consuming and inefficient" situation has not been fundamentally changed [2]. Guided by the theory of education ecology, this paper, based on the analysis of college English education ecological system structure and characteristics, analyzes the difficulties, parsing, reasons and countermeasures faced by college English education in China. In addition, combining with teaching practice, the ecological education mode is explored and applied, which provide guide for deepening the reform of college English education.

\section{The Structure and Characteristics of the College English Ecosystem}

The idea of education ecology was first proposed by American educator Laurence creaming. From the perspective of the education ecology, college English education can be thought of as composed of unique ecological principals and ecological environment, affected by the system inside and outside factors of organic and complex ecosystem [3]. The main body of the system is students and teachers. Teachers are the main body of the teaching, and they are the architect, the organizer, the guide of the teaching activities, and play the guiding role. The students are the subjects of learning, who are the receiver of the information, the stockman, and at the center of the teaching activity. The concrete composition structure is shown in Figure 1.

College English education ecological system has the integrity of the natural ecosystem balance, connecting, and also has the openness, purpose, order of education ecological system, at the same time also has its own special properties, embodied in three aspects. The first is interactivity. The carrier of education in college English is the language, and the language itself is communicative and its application is inseparable from the situation. To cultivate and improve the students' English comprehensive application ability, especially listening and speaking skills, on the one hand, it needs teachers and students strengthen the communication and interaction in the classroom teaching and network autonomous learning, On the other hand, Students need to get out of the classroom and create communication opportunities and improve their communication skills. The second is professionalism. An important mission of university, different from the primary and secondary schools, is to cultivate professional talents with international vision. Public English education must obey and serve the mission and objectives. Therefore, we should set up English courses according 
to the students' specific majors and combine English learning with professional learning. At the same time, we will develop the ability of students to conduct professional research and conduct international academic exchanges in English. The third is cultural. In college English education in our country, we should adapt to economic globalization and the strategic need of further opening wider to the outside of the country, pay attention to cultivate the students' cross-cultural communication ability, help them to communicate with foreigners appropriately and effectively, but also set up the confidence of the Chinese nation culture, train the students' ability to use English to spread Chinese culture.

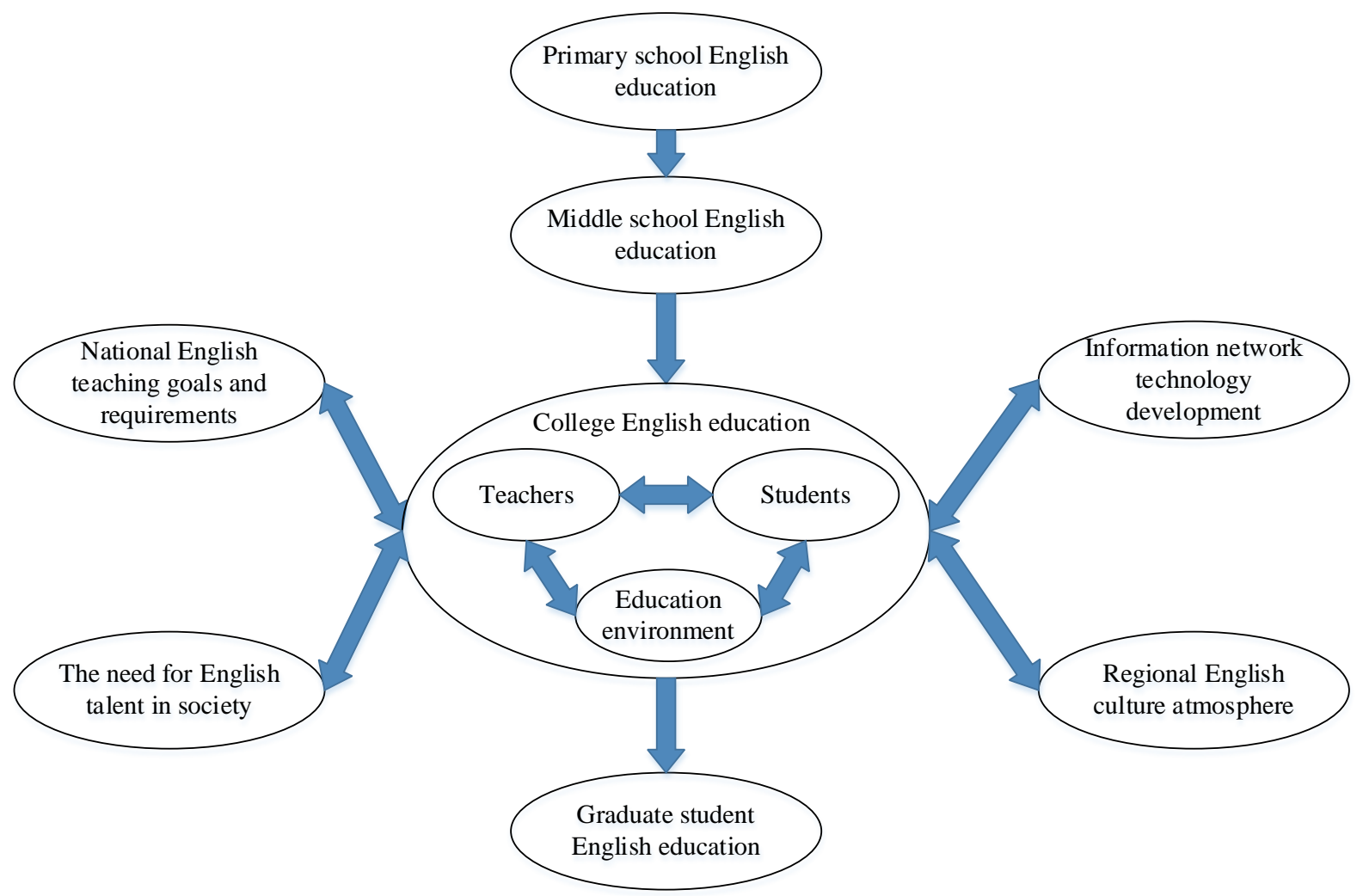

Figure 1. College English ecosystem

\section{The Predicament and Ecological Analysis of College English Education in China}

According to the reform and deployment of the ministry of education, the new English teaching model has been adopted in most colleges, but the results are not obvious [4]. Arguably, education is facing an unprecedented dilemma, even an "ecological crisis". Through the analysis from the perspective of education ecology, the causes of this dilemma is various, including ecological main body itself, the ecological environment influence, the internal environment of school, and the external environment of school. The main performances are in three aspects, as shown in Figure 2.

The Status of the Ecological Subject is Unbalanced and Lacks Interaction. The first is the ecological imbalance of the teachers and students, and the lack of effective communication and interaction. Traditional English teaching is basically teachers monologue type and one-way infusion. The students lose its ecological niche, become passive, and have less interaction between teachers and students. Secondly, the student's central position is not outstanding, lack of the independent choice of study. English education should highlight the students as the center. But in the actual teaching, it is basically "teaching". In the management system, training target, resource allocation, teaching evaluation, it always emphasizes the unification and standardization, which causes that students cannot choose the suitable English course according to professional characteristics and the individual demand. It can not mobilize students' learning enthusiasm and initiative, and is unfavorable to the cultivation of students' autonomous learning ability. 


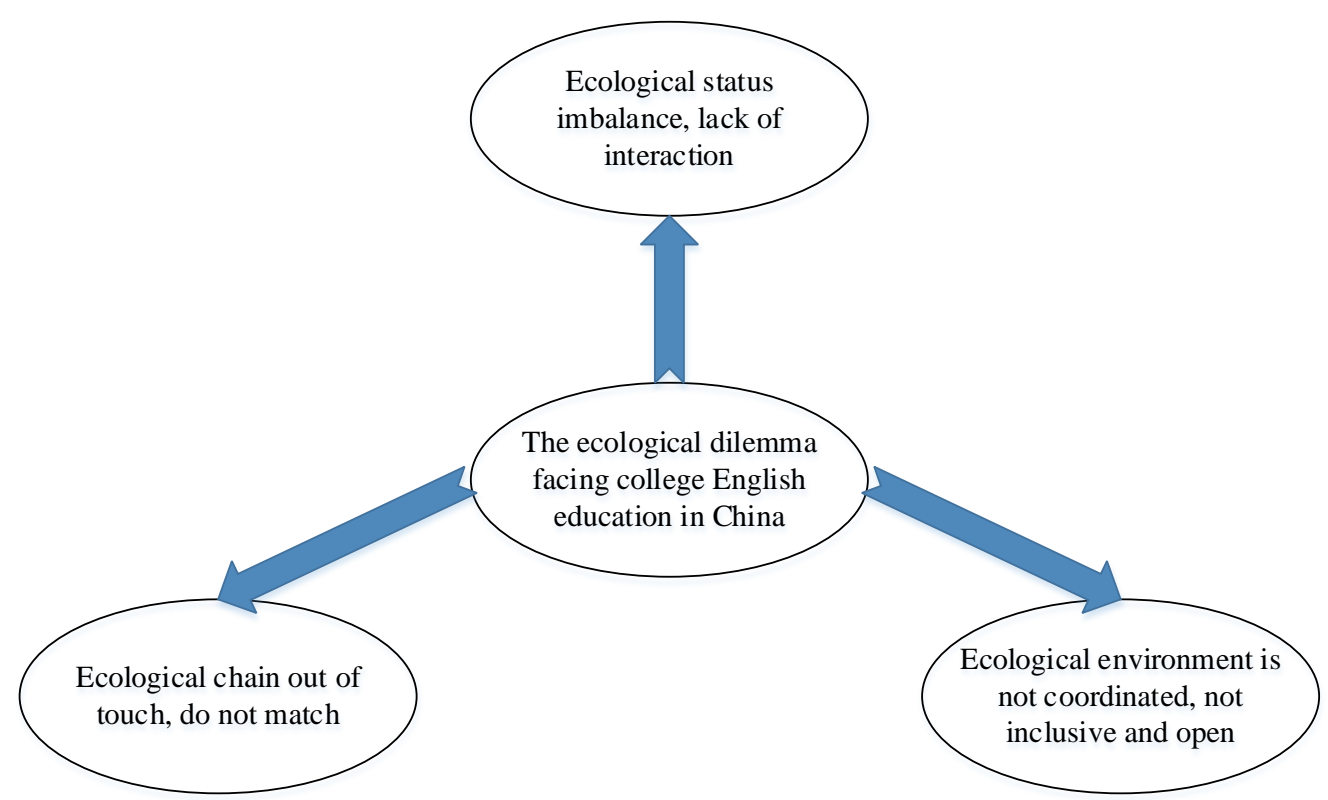

Figure 2. The ecological dilemma faced by college English education in China

The Ecological Chain is out of Touch and does not Match. From the education system of primary and middle school English, although our English education starts from primary school, it will take 12 to 14 years to graduate from university. However, due to the lack of top-level design, the teaching objectives and requirements are incoherent, and the teaching material is not cohesive. Many of the basic knowledge learned in the middle school stage are repeat studied in the college stage. In addition, English learning in college stage can not be closely integrated with the professional. Students lack of autonomy in choosing courses. This will not only result in the waste of educational resources and the ineffectiveness of education, but also not conducive to the formation of college English education and quality improvement. From the perspective of college English education itself, the chain among the educational goals, content, methods, evaluation and even the social needs does not match.

The Ecological Environment is Uncoordinated and not Inclusive. From the physical environment, English teaching is suitable for small class and interactive teaching. But with the expansion of college enrollment in China, English teaching student-faculty ratios imbalance phenomenon is outstanding, coupled with the limited language lab and other teaching facilities. Most colleges use large classes, which is not conducive to teachers in accordance with their aptitude, personalized teaching, and seriously affected the interaction between teachers and students. From the point of organizational environment, the vast majority of public English teaching in colleges is given priority to with classroom teaching, relatively closed, lack of openness. From the mental environment, the intrinsic motivation of the students to learn English is not strong, and the utilitarian is obvious.

\section{The Construction of Ecological Model of College English Education}

This paper argues that it is an effective way to get out of the difficulties of college English education under the guidance of educational ecology theory and explore the establishment of eco-education model which is in line with the ecological law, student - centered, interactive, open, autonomous and harmonious. In general, this ecological education model is the all-round change of the original educational model, involving all aspects of college English education. Its main content includes five aspects, as shown in Figure 3.

Ecological Goal of Education. One is comprehensive. College English courses are both instrumental and humanistic. Their educational goals should include knowledge objectives, competency goals, cultural goals, emotional goals and so on. The second is hierarchical. In the actual teaching, colleges should adhere to the concept of "biodiversity". With the goal and requirement of national unity, the students of different specialties, different English bases and 
different vocational needs are combined to make practical and multi-level teaching objectives. The Third is coherence. Strengthen the top-level design of English education for primary and middle schools and college. Primary and middle English education should focus on laying the language knowledge base, cultivate the comprehensive application ability. College English education should improve the comprehensive application ability and intercultural communication. Graduate stage should strengthen academic English learning, train English academic exchange and academic research capacity.

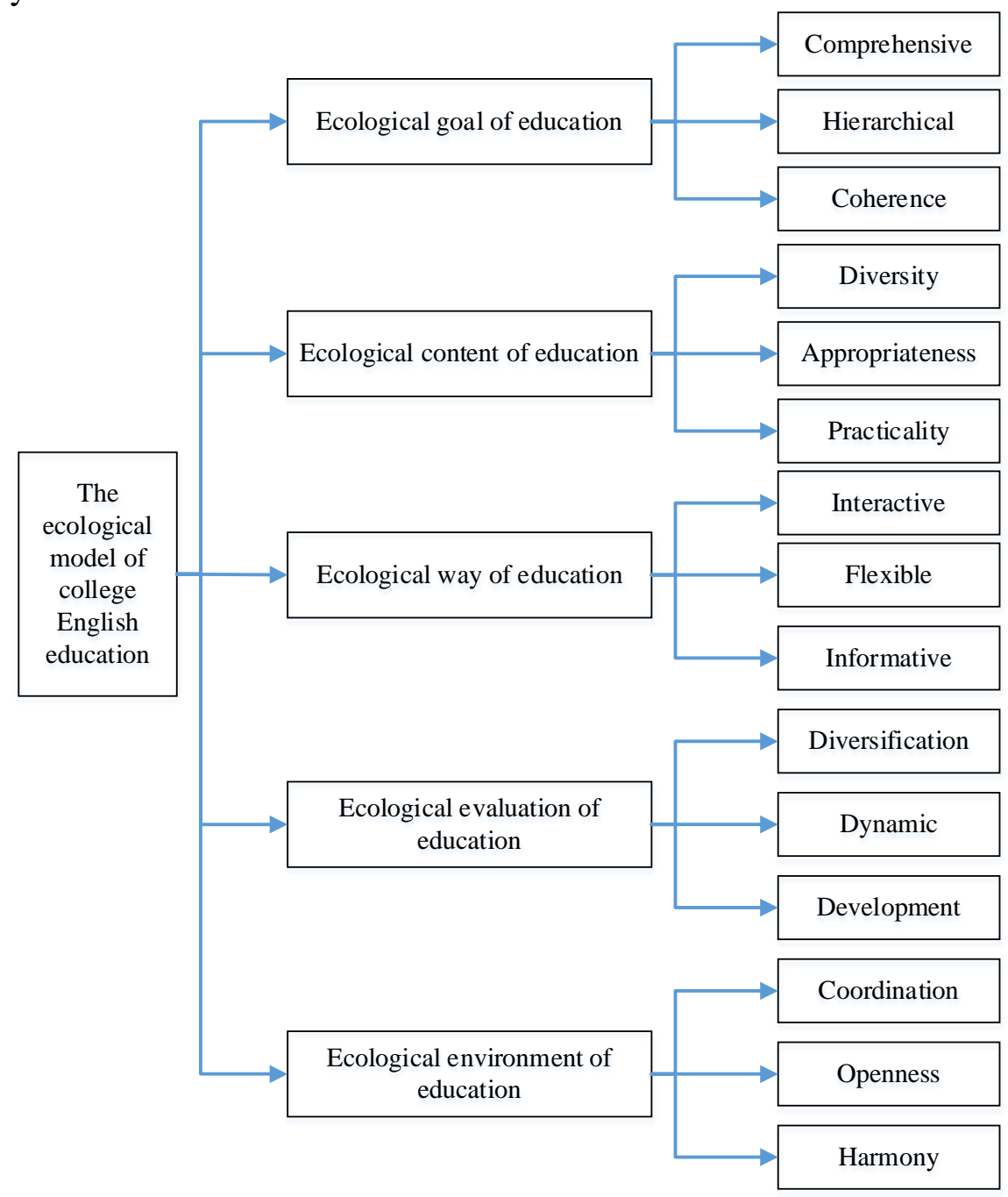

Figure 3. The ecological model of college English education

Ecological Content of Education. The first is diversity. Guide and encourage students to use unified teaching materials. At the same time, considering their own professionalism, English proficiency and learning interest, the teaching resources inside and outside the college should be organically combined. The second is moderate. According to the principle of ecological tolerance and the most appropriate principle, for different educational objects, grasp the number of teaching content, difficulty, in order to better achieve the teaching objectives and requirements. The third is practical. The purpose of learning language is to apply. Teaching can choose some of the teaching content, financial science, fun and practical in one of the topics to carry out exchange discussions, create more application scenarios, in order to stimulate students to learn interest and meet the actual needs of communication.

Ecological Way of Education. The first is interactive. Pay attention to the use of interactive teaching method. Through effective communication and interaction, students' interest and potential to learn should be stimulated, in order to better play the teacher's subjective initiative, and achieve collaborative development. The second is flexibility. For the students' personality characteristics, English foundation, specific professional, the flexible and diverse teaching and communication methods should be implemented in order to promote students personalized development. The third 
is information. The information network technology and English curriculum should be integrated, so that computer multimedia teaching becomes normalization.

Ecological Evaluation of Education. Combined with the summative assessment and formative assessment, evaluation on a regular basis and regular evaluation, external evaluation for teachers and students self evaluation, the education goals and requirements should be fully reflected and the functions of guidance and supervision will be played well. In the evaluation of the main body, pay attention to the self-evaluation of students and the mutual evaluation between students. In the evaluation of contents, focus on learning attitude, methods, strategies and other self-learning ability. In the evaluation of activities, focus on the performance evaluation of student participation in activities, exchange and other aspects.

Ecological Environment of Education. The first is coordination. The teaching facilities and equipment and other hardware conditions, teaching management, the psychological state and motivation of teachers and students and other software conditions should be coordinated with the teaching needs. The second is openness. Through the teaching content, organizational form, cultural atmosphere and other internal and external opening, it should break the time and space boundaries of traditional teaching, and create a good language learning environment and exchange exercise opportunities. The third is harmony. Teachers and students should strengthen emotional exchanges, establish the equal dialogue and create a trust, mutual aid, harmonious education atmosphere.

\section{Practice and Suggestion on the Ecological Model of College English Education}

Establish a Student-centered Educational Philosophy. The design of teaching plan, the selection of teaching content, the organization of teaching activities, the use of teaching methods and the teaching evaluation should all be implemented from the student's actual situation and demand. In addition, increase the student's learning autonomy and the proportion of elective courses, so that students have more choice [5].

Create an Open, Integrated Education Ecological Chain. On the one hand, the English education should be extended from the classroom, which will enable students to show their talents in different situations and improve the communication and practical application of English. On the other hand, the English education should also focus on the classroom. It is necessary to organize the students to have English application requirements of unit internship training, let the students have more opportunities to gain experience and exercise.

Create a Coordinated Development, Open and Harmonious Educational Ecological Environment. It is necessary to increase the effective input, strengthen the real language studio, multimedia classrooms and other teaching facilities and equipment construction, try to control the class size, and create a moderate classroom environment. According to the college's own characteristics, professional settings and students demand, the independent advanced teaching software ought to be introduced in order to provide support to carry out eco-English education. Through playing classic English movies, interspersing cultural background introduction, western culture and customs will be learned by students, which also can enhance cross-cultural communication skills of students.

\section{Conclusion}

Regard the education ecology theory as the instruction, and build the education ecological model of college English according to the concept of education, which is "based on student". The fundamental purpose is to out of the plight of the college English education in China. To promote the implementation of education target and students' sustainable developments, is in line with the development law of language teaching and the direction of teaching English reform in China. But as an emerging interdisciplinary subject, its theory and practice have yet to be further discussed and improved, which needs the joint efforts of English education researchers, government departments, teachers and students. 


\section{References}

[1] Liu Haifen, Zhang Caiyun. On the Predicaments and Strategies of College English Education in the West of China from the Perspective of the History of Our Country's English Teaching [J]. Journal of Yanan University ( Social Science), 2006, 28(3): 122-125.

[2] Cao Yanyan. Research on the Realistic Dilemma and Countermeasures of College English Education Reform [J]. College English, 2013, 10(2): 298-301.

[3] Xu Lihua. An Analysis and Countermeasures on the Dilemma of College English Multimedia Teaching [J]. Journal of Liaoning Administration College, 2008, 10(10): 155-156.

[4] Zhao Yin. Problems and Countermeasures to College English Follow-up Education [J]. Journal of Changzhou Vocational College of Information Technology, 2012, 11(1): 79-81.

[5] Liang Yanhong, Li Qin. Investigation and Countermeasure on Lack of Chinese Culture in College English Education [J]. Journal of Hubei University of Education, 2014, 31(11): 40-42. 